\title{
Choosing Computing: How and Why Women Enter Computing Through Coding Bootcamps
}

\author{
Krista Schnell \\ kkschnell@berkeley.edu \\ Department of Sociology \\ University of California, Berkeley
}

Keywords: gender, work and occupations, science and engineering, computing

Abstract: Current shortcomings of the pipeline and life course model, as well as negative tech culture discourse, underestimate the potential and resilience of women in computing. Women may be pushed out of computing in their youth, but they can come back - and they do. Using data from in-depth interviews with women graduates of coding bootcamps (accelerated programs that teach beginners digital skills), this study provides empirical data on how and why women enter computing later in life, often after having non-technical degrees and careers. This study finds that to successfully enter the computing workforce, women must arrive at three end states, which are often achieved via three transitions: "I can't code" to "I may code;" "I'm on another path" to "I want to code;" and "I can code" to "I do code." In addition, this study finds surprising evidence of women choosing to enter computing for better pay and work-life balance, in contrast to research that suggests women leave for these reasons. Rather than add to the extensive literature on why women leave, this article highlights how and why women enter computing and overcome the odds stacked against them.

Acknowledgements: I am grateful to Danny Schneider and Jenna Johnson-Hanks for their excellent guidance and feedback. Many thanks to Isaac Dalke, George Kulakowski, Sigrid Luhr, Raka Ray, and Skyler Wang for their generative comments and support. A previous version of this paper was presented at the Gender \& Sexualities Workshop at UC Berkeley, and I thank the participants for their helpful feedback. 


\section{Introduction}

Recent news coverage by The Atlantic and The New York Times exposed the blatant and subtle sexism, as well as sexual harassment, that women in the tech industry often face (e.g. Benner 2017; Mundy 2017). They depict an overtly hostile culture, pushing women out of techbut common cultural scripts often discourage women and girls from tech and technical work in the first place. An anti-diversity memo published by ex-Google employee James Damore and comments by Harvard University president Larry Summers both suggested biological reasons for why women are less suited for technical fields. It may come as no surprise then that women continue to remain outnumbered in many science and engineering $(\mathrm{S} / \mathrm{E})$ fields, especially computing. While women make up nearly half of the U.S. workforce (BLS 2018), they held only $28 \%$ of all S/E jobs in 2015 (NSF 2018, Appendices 3-26) and 25\% of information technology (IT) jobs in 2014 (Beckhusen 2016). And while women graduate with over half of all bachelor's degrees and about half of all S/E degrees (NSF, NCSES 2019), they make up only $20 \%$ of engineering and 18\% of computer science graduates (NSF 2019, Appendices 2-21). Despite investments in research and programs to increase the percentage of women in S/E (Committee on Maximizing the Potential of Women in Academic Science and Engineering and Committee on Science, Engineering, and Public Policy 2007), representation in engineering and computing remains low (Beckhusen 2016; NSF 2019, Appendices 2-21). ${ }^{1}$

To explain this gender gap in S/E and computing specifically, the metaphor of the "leaky pipeline" is often invoked (e.g. Alper 1993; Berryman 1983; Camp 1997). In short, it assumes

\footnotetext{
${ }^{1}$ According to NSF, S/E encompasses both educational and occupational fields, including: biological and agricultural sciences; computer sciences; engineering; mathematics and statistics; physical sciences; psychology; and social sciences. According to BLS, information technology (IT) refers to those who work in computer and information technology occupations, includes computer programmers among other job titles. Computing refers to computer science (CS) and CS-related education or IT occupations. I use technical degrees or technical work to refer to educational studies or occupational work, respectively, in computing, engineering, and the physical sciences.
} 
that there are relatively few women who take an interest in computing — due to gender socialization, for instance (Eccles 1987; Jacobs 1989; Marini and Brinton 1984; Parsons and Bales 1955) — so few study computer science and subsequently get jobs in the field. For those women who are in the pipeline, there are multiple exit-points along the way; they could drop out due to experiencing a "chilly climate" in college (Crawford and MacLeod 1990; Hughes et al. 2017; Seymour and Hewitt 1997; Xie and Shauman 2003) or difficulty balancing long work hours with family obligations (Ceci and Williams 2011; Frehill 2012; Preston 2004), to name a few. Significantly, this pipeline metaphor assumes a single linear trajectory from interest in to studying to working in computing, disregarding the possibility that anyone could re-enter the pipeline later in life — and overcome the setbacks that previously pushed them out.

Scholars who advocate for a life course model, however, recognize the many phases and changes that occur in a person's educational and occupational life. In this way, they challenge the pipeline model and demonstrate that, in fact, women can and do change directions educationally and occupationally (Jacobs 1989; Rosenfeld and Spenner 1992; Xie and Shauman 2003). Unfortunately however, much of the literature on individual mobility does not consider $\mathrm{S} / \mathrm{E}$ specifically, and the vast majority of research on $\mathrm{S} / \mathrm{E}$ and computing fails to consider women post-college. Critically, these studies largely ignore those women who change course to enter $\mathrm{S} / \mathrm{E}$ later in life and the processes by which they do so. One reason for this (in addition to the prevalence of the pipeline model) could be that in the past, a transition to computing was quite difficult and often required some sort of technical background, along with multiple years in college and a significant monetary investment.

While the pipeline perspective has severe limitations, the life course model lacks empirical data on women who transition into computing post-college and how and why they do 
so. Recently, however, coding bootcamps_ or "intensive, accelerated learning [programs that teach] beginners digital skills" (Eggleston 2015) — have emerged to make the transition to computing a bit easier. In 2018, a surprising 37\% of all coding bootcamp graduates were women. Since the average bootcamper is " 30 years old, has 6 years of work experience, has at least a bachelor's degree, and has never worked as a programmer" (Eggleston 2018a), coding bootcamps are an ideal site to identify and learn from women who transition into computing later in life. Theoretically, the odds stacked against these women are greater — not only have they often spent more time studying and working in non-technical fields, but they likely have also received more subtle or overt messages that computing is not for them. So why now? How do these women come to realize that computing is an option for them, and what are their motivations to pursue it, especially in light of popular depictions of tech culture? Finally, what are the means by which they attend a coding bootcamp and achieve their goal of working in tech as a programmer?

To shed light on the processes by which women are enabled and incented to enter computing later in life, I conducted 16 in-depth interviews with women and other femmepresenting individuals, who attended a coding bootcamp with the goal of getting a job as a software developer in tech. 13 of 16 respondents majored in non-technical fields in college, and the same number came from non-technical jobs or careers. All were aware of and believed the negative depictions of tech culture. Still, they chose to pivot to computing - and for the 12 of 16 who actively sought software development jobs after graduation, all successfully obtained one within six months or less. By gaining an in-depth understanding of these women's educational backgrounds and work experiences prior to attending a coding bootcamp, I was able to identify three critical transitions to end states which needed to be achieved before these women could 
successfully enter tech as programmers. First, many of the women had to overcome narratives that said coding was not for them in order to consider computing as a viable career option.

Second, women had to be in situations which caused them to look up and consider other paths, in order to be pulled into and motivated to pursue computing. And third, they needed to have the money and time to attend a coding bootcamp and the resources to get a job as a software developer in tech.

I also discovered that these women sought jobs in tech, despite their knowledge of the industry's toxic culture. Interestingly, several respondents said they believed and then confirmed that tech culture was in fact no worse than that of the industries from which they came-contrary to popular notions that tech is uniquely bad to women. Importantly, however, these women stated that working as a programmer in tech came with notably better benefits, including a higher salary and more flexible working conditions, which led to a better overall lifestyle. These data conflict with findings that women leave technical jobs due to work pressures and difficulties balancing work and family (Ceci and Williams 2011; Hewlett et al. 2008; Stephan and Levin 2005) and, in part, due to dissatisfaction with pay and promotion (Hunt 2016). However, these data support recent quantitative research which argues that a lack of mentorship and networks, as well as discrimination, explain high exit rates of women from engineering and computing (Hunt 2016).

While the leaky pipeline model fails to leave room for women to enter computing later in life, the life course model falls short of providing empirical evidence for how and why women enter computing, especially post-college. The rise of coding bootcamps and their relatively high graduation rates of women, however, provide an ideal opportunity to study those women who enter computing, even after having had non-technical degrees and careers. As such, I take up the 
strategic site of coding bootcamps to provide empirical data on the processes by which women are enabled and incented to enter computing — thus developing the life course model and filling a current gap in the literature. Moreover, I find surprising evidence of women entering computing for better pay and work-life balance, in spite of tech's poor workplace culture. I argue that current shortcomings of the pipeline and life course model and negative tech culture discourse underestimate the potential and resilience of women in computing - they can come back, and they do. Furthermore, greater recognition of tech benefits to women - instead of uniformly negative coverage — could serve to recruit more women to computing, especially in a career transition. By continuing to focus news and research on why women leave computing rather than why they enter, we risk deterring women from computing, despite our intents to the contrary.

\section{Explanations for Women's Underrepresentation in Computing}

\section{Women in $\mathbf{S} / \mathbf{E}$}

For decades, scholars have been interested in why there are so few women in S/E. Major motivations behind this research have been to reduce occupational gender segregation and the gender pay gap (Lim 2016; Michelmore and Sassler 2016; St. Rose 2010), and to improve productivity and innovation in S/E fields (Hunt et al. 2013; Lehman, Sax, and Zimmerman 2016; Margolis and Fisher 2003). While computing and IT fields may come with additional challenges for women (given their unique decline in representation), the factors that dissuade women from entering $\mathrm{S} / \mathrm{E}$ also hold for computing, a subset of the broader category.

There are a variety of reasons given for why women do not pursue S/E. Drawing from economic theory, scholars often organize these reasons into two general camps: "supply" and “demand" (Ecklund, Lincoln, and Tansey 2012; Thébaud and Charles 2018). The supply-side 
refers to those who invest in the appropriate computing education to be prepared for work in $\mathrm{S} / \mathrm{E}$ (Becker 1985; Mincer and Polachek 1974). Arguments have been made that workforce patterns are rooted in biological gender differences (Ceci and Williams 2011; Ceci, Williams, and Barnett 2009), but social scientists reject these explanations. Instead, gender-role socialization and early educational experiences are often used to explain why girls are less likely to show an interest in S/E subjects (Ecklund et al. 2012; Farmer, Wardrop, and Rotella 1999; Margolis and Fisher 2003; Sonnert and Holton 1995; Thébaud and Charles 2018). Due to powerful gender norms starting in early childhood (and lasting throughout one's life), boys and girls are socialized to conform to their respective gender roles and pursue gender-typical careers (Eccles 1987; Jacobs 1989; Marini and Brinton 1984; Parsons and Bales 1955). Since S/E fields are considered to be masculine domains that glorify stereotypically masculine traits (Bailyn 2003; Cooper 2000; Faulkner 2000; Hacker 1989; McIlwee and Robinson 1992), girls may avoid these fields out of fear of being seen as unfeminine (Kelly 1985; Matyas 1985; Tai, Sadler, and Mintzes 2006). In addition, research has identified myths like the "brilliance narrative" (that one must have raw, natural intelligence) and "geek" stereotype (that one must be singularly obsessed with S/E) that have been shown to map onto the underrepresentation of women in S/E disciplines (Meyer, Cimpian, and Leslie 2015) and to be more detrimental to women than men (Margolis and Fisher 2003). Finally, experiences in academics can push girls away from S/E, due to lower expectations from teachers (Becker 1981), a lack of role models (Bottia et al. 2015; Marx and Roman 2002), and a "chilly climate" (Crawford and MacLeod 1990; Hughes et al. 2017;

Seymour and Hewitt 1997; Xie and Shauman 2003).

On the other hand, demand-side explanations come from companies and employers in the S/E labor market (Becker 1985; Ecklund et al. 2012; Thébaud and Charles 2018). Studies show 
that women leave $\mathrm{S} / \mathrm{E}$ occupations at a higher rate than men, often to go to another field (not to leave the labor force) (Frehill 2012; Glass et al. 2013; Preston 1994, 2004), and that that high exit rate is driven by engineering, including computing, specifically (Hunt 2016). As women in a male-dominated workplace, they may feel isolated as minorities (Kanter 1977; Michelmore and Sassler 2016) or experience outright discrimination in terms of hiring, pay, or promotion (Becker 1957; Heilman 2001). Some reasons for why women leave S/E specifically include dealing with extreme work pressure, facing a macho culture, disappointments with compensation (Hewlett et al. 2008), long hours, and difficulties balancing work and family life (Ceci and Williams 2011; Stephan and Levin 2005). Recent research, however, has specifically deemphasized the role of the family in women's exits from S/E (Frehill 2012; Glass et al. 2013; Hunt 2016). Frehill (2012) finds that women's "changes in career or professional interests" is more important, while Hunt (2016) finds that disappointment with pay and promotion is the leading factor for why women leave. Hunt (2016) argues, "The implication is that a lack of mentoring and networks, or discrimination by managers and co-workers are the more promising of the existing explanations for excess female exits" (p.221).

\section{Pipeline and Life Course Models}

One model that is frequently invoked to explain this gender gap is that of the "leaky pipeline" (e.g. Alper 1993; Berryman 1983; Camp 1997). In short, a pipeline assumes that there is a tight coupling between one's education ("supply") and subsequent work ("demand") in S/E, and leakage or attrition occurs for women all along the way. According to this model, women either choose to study S/E early on and continue forward on the path, or they are nudged out. Significantly, once one has left the pipeline, the model provides no entryways back. There are no opportunities for changing majors, mid-career pivots, or delayed entrances - even though other 
research has shown that there is a good deal of mobility across an individual's career (Jacobs 1989). What the leaky pipeline model gets right is that women are frequently faced with social pressures that add up over time and push them away from computing, and the popularity of this model has led to considerable research focused on early childhood socialization and education through the college years, as well as significant investments to retain girls in S/E during this time (Xie and Shauman 2003). While these are certainly important years in a girl's life, this research fails to consider women who may wish to enter computing for the first time later in life, even after attaining a non-S/E degree and pursuing a non-S/E career.

As an alternative to the leaky pipeline model, Xie and Shauman (2003) suggest a life course model that takes into consideration a much broader range of possible life events. In support of this model, they demonstrate that a significant number of students shift from non-S/E to S/E majors during college, and "gender differences in the prevalence of this 'nonconventional' path to S/E account for almost half of the gender differences in S/E attainment" (p.212). Contrary to what the leaky pipeline model would predict, this shows that women can change direction and enter S/E, even after high school, when their originally intended major was not S/E. However, Xie and Shauman's (2003) quantitative data cannot speak to individual transitions from S/E degrees to S/E careers or individual mobility into and out of S/E careers-nor how or why these individual changes might occur. Furthermore, computing, which other research suggests may differ from other S/E subfields, is not investigated specifically.

Similarly, in Jacobs's (1989) study of women's careers and gender segregation in the workforce, he argues against the cumulative disadvantage model—that obstacles accumulate over time for women (implicit in the pipeline metaphor)—and advocates for a "revolving door" model instead, which "can account for extensive sex-type mobility because it recognizes a 
variety of stages in the career development process, and it recognizes a host of pressures women face" (p.52). Unlike Xie and Shauman (2003), Jacobs's data can and do speak to individual-level mobility between male-, women-, and neutral-typed jobs, which is found to be quite common. Jacobs argues that lifelong mechanisms of social control are required to maintain the overall high degree of gender segregation in the workforce. This is a particularly useful model to consider with respect to women entering computing later in life. Still, one drawback of Jacobs's study (which he readily admits and calls for in future research) is that it cannot address the actual factors that influence women to pursue male-dominated professions, and certainly not why women change career paths to enter male-typed careers. Second, this study was conducted at a time in which women were at their peak in terms of representation in computing - there was nothing unusual about the field at the time. Therefore, it is worth considering the factors which now impact women's decisions to transition into the male-typed domain of computing.

\section{Multiple Paths to Computing}

Very few academic articles acknowledge that women can enter computing later in life, even though alternative pathways, including those without formal education, have always existed. Moreover, many of the studies that actively argue for a life course model stop at the college years and do not consider post-college. That being said, a small handful of studies have considered multiple entryways into computing. In a study of women in IT in Australia, von Hellens et al. (2002) found that of the ten women in IT they interviewed (from the "Women in Technology network," as part of a larger study), the majority switched into IT early in their careers, "when they were exposed to computing and realized that they liked it... They had come into IT almost by chance at a point in their lives when they were dissatisfied with what they were doing, saw the opportunities, and realised that they had the aptitude" (p.154). Interestingly, these 
women's transitions seem surprisingly straightforward and easy according to the article, and they are not discussed in depth.

In Leventman's (2007) study on multiple pathways into the IT workforce, she creates a typology of three main paths people take to careers in IT, based on IT professionals recruited from four corporations and Northeastern University's Master of Science in Information Systems (MSIS) program. These paths are Traditional, Transitional, and Self-Directed, and a woman's career profile is highlighted to illustrate each. The Traditional path follows the pipeline model, in that women decide they want to be in IT during high school or college, and then they work in IT throughout their career. A person on the Transitional Path typically decides they want to work in IT after receiving a non-technical degree and while working in a non-technical field, and then they attend a graduate program (like MSIS) to make the career transition possible. Finally, the Self-Directed path looks very much like the Transitional path, except they do not attend a graduate program but learn on their own. While this study benefits from a large sample size (as part of a larger Northeastern University IT Workforce Study), the women's actual motivations and means to make this career transition into IT are not discussed. However, outcomes are provided, which indicate that those who transitioned into IT "doubled or tripled their preprogram salaries, achieved high organizational positions, and expressed relatively high job satisfaction" (p.216).

The most relevant research on women's motivations to enter IT was conducted by Turner et al. (2002), by surveying women on an email list for Systers, an organization for technical women in computing. They found that "A surprising number (31\%) [of 275 survey respondents]... majored in the arts, social sciences, or humanities as undergraduates and entered the IT field through non-traditional means, primarily as a result of on-the-job experiences" (p.7). 
Based on answers to the survey questions, they were able to identify high-level external influences of people and experiences, as well as internal motivations, that influenced these women's decisions to enter IT. In terms of important people, they most often cited colleagues at work, friends in IT, or mentors. Their most influential experiences were usually obtained on-thejob, gaining exposure to IT work. Finally, though they stated enjoying their work in IT, they more often mentioned choosing the field due to "having an ability or skill" (p.14) as an internal motivating factor. This research is both informative and insightful and should be applauded for its ability to compare relatively large samples of women in IT from different educational backgrounds, highlighting multiple pathways into IT. However, these women's paths and motivations might be quite different almost two decades later, especially given the pace of change in the IT field. These women were surveyed in 2001, when these women who majored in non-technical fields had been working in IT for an average of 9.7 years - meaning they would have entered IT around 1990, just several years after the peak of women in computing and IT. In addition, this study only considers those factors that pulled women into IT and not the situational factors that may have pushed women out of other careers nor the means that made the transition possible. Significantly, this study was conducted at a time in which there were far fewer opportunities for women to make a relatively quick, intentional pivot to IT, especially coming from non-technical backgrounds.

To summarize, the pipeline model is prevalent, but it fails to explain how individuals change course throughout their lives, either through education or work. The life course model provides an alternative explanation that can account for multiple pathways and non-linear career trajectories, but it also has empirical holes. In terms of $\mathrm{S} / \mathrm{E}$ and computing in particular, the vast 
majority of research falls short of demonstrating that women can and do enter computing postcollege, as well as how they do so.

\section{Methods}

To shed light on the processes by which women enter computing later in life, I set out to conduct in-depth interviews with women who attended a coding bootcamp.

In comparison to graduate programs, other training programs, or professional groups, coding bootcamps are a strategic site for research because they graduate relatively high rates of women entering computing for the first time later in life. As mentioned previously, coding bootcamps make it significantly easier for those with non-technical backgrounds to transition to computing, since they are accelerated programs specifically designed to teach beginners digital skills (often in web or mobile development) in preparation for jobs in the tech industry (Eggleston 2015). To be more specific, the average bootcamper has a bachelor's degree and prior work experience, though not as a programmer (Eggleston 2018a), and the average bootcamp is 14.3 weeks long and costs $\$ 11,900$ (Eggleston 2018b). So far, this model has been very successful. Though the first coding bootcamp opened in just 2012, by 2018, there were 108 coding bootcamps across the U.S. and Canada, graduating 16,593 students (Eggeston 2018b). Graduates start with an average salary of \$64,528 (Eggleston 2018a). Perhaps even more surprising, however, are the gender demographics. In 2018, 6,140 women graduated from coding bootcamps - a sizeable number in comparison to the 13,654 women who graduated with computer and information sciences bachelor's degrees in 2017 (NCES, IPEDS 2018, Table 322.50) - making up 37\% of the total (Eggleston 2018a). Given that $19 \%$ of computer science majors in 2017 (NCES 2018) and 25\% of the IT workforce in 2014 were women (Beckhusen 2016), 37\% is an incredibly high number. For these reasons, coding bootcamps serve as an ideal 
site to identify women who enter computing for the first time later in life and to study the processes they go through to do so.

After first obtaining IRB approval in the early summer of 2018, I began to recruit respondents through my network in Silicon Valley, a major hub of coding bootcamps. During that time, I also attended six in-person coding bootcamp information sessions and one online information session to gain a better understanding of coding bootcamps' curriculum, work space, instructors, and how they market themselves to prospective students. These sessions were available to the public (though they often required one's name and email address through an online RSVP form), and when making introductions, I identified myself as a researcher to all attendees, including coding bootcamp instructors and prospective students alike. Typically, these information sessions were about an hour long, concluding with a quick tour of the workspace and time for questions at the end. I took notes on my mobile phone during the information session, and I referenced them to write longer memos once I returned home. I found this initial ethnographic research to be particularly valuable in informing the creation of my interview schedule.

My first four respondents were recruited through my network of tech professionals, since I have lived in Silicon Valley for the last ten years and worked in tech for five of them. Many of my interviewees offered to connect me to someone they knew who had attended a coding bootcamp, but some of the first few also offered to post my information to their coding bootcamp's online alumni communication channel. This led to the recruitment of 11 of the next 12 respondents, which is why so in my sample attended the same several coding bootcamps. Given that certain types of people might self-select into specific bootcamps, this likely narrowed the types of respondents in my sample (though it is possible I could have had a similar outcome 
through a more traditional method of snowball sampling). Interested participants were given a link to my personal website, which provided a short description of the study and another link to schedule an interview, either in-person at a location of their choice in the Bay Area (which I indicated as my preference, if possible) or online through a Google Hangouts video chat (10 interviews were conducted in person and six online).

The interviews were semi-structured and lasted between 45 to 90 minutes. My goal was to gain an in-depth understanding of the ways in which these women came to consider and then were motivated to attend a coding bootcamp. I asked about their educational history, to gauge why they might not have studied computing in the past, and their work history, if applicable, to see how it related to their subsequent career transition. In addition, I asked about how they financed their coding bootcamp education and any barriers or worries they had in making their transition to software developers in tech. Finally, I asked how they felt about coding, their new career, and working in tech. While this was the basic outline of my interview, respondents could skip any questions or add more detail where they liked. I audio-recorded all of the interviews, and once complete, I personally transcribed and coded them. I began the coding process by identifying a large number of small themes, and from there, I categorized them into larger umbrella concepts. All names used are pseudonyms, and approximate ages are given.

In July and August 2018, I interviewed 15 people who identify as women and one genderqueer person who presents as a woman ${ }^{2}$, who previously attended a coding bootcamp. (I also interviewed five men, but their data is not discussed in depth in this paper; still, my interviews with them helped paint a larger picture of coding bootcamps and their attendees.)

\footnotetext{
${ }^{2}$ Because a female identity has been very important in this genderqueer person's life, I will include them in the term women to refer to the group of respondents from here onward. However, when providing individual quotes, I will specify each person's preferred gender identity.
} 
Though successful completion was not required, all respondents graduated from their respective coding bootcamps. As is typical of coding bootcamp demographics, my respondents were overwhelmingly White and Asian and had at least a bachelor's degree, but they represented a variety of hometown locations (all but one in the U.S.) and SES backgrounds. 13 out of 16 respondents had a non-technical college degree, and the same number worked in a non-technical field prior to attending a coding bootcamp. (See Table 1 for demographic data.) In other words, these women would never be predicted to enter computing according to the pipeline model—and they have been mostly ignored by life course model advocates. As such, these women are ideal candidates to provide insight into how and why women choose to enter computing later in life.

\section{Data and Discussion}

In order for women to enter a career in computing by way of a nontraditional coding bootcamp education, three end states must be achieved, which are typically accomplished via three transitions (though they may and often do occur in a different, less linear order than the one I present here). (A) As the literature would predict, many of these women did not initially see computing as a viable option available to them. Some have bad experiences and others have limiting narratives that tell them (A1) they can't code, which they must first overcome to believe that (A2) they may code. (B) Women next need to have a reason to look up from the path they are on in order to be drawn into computing and want to code. My findings indicate that situational factors (by chance or choice) (B1) push women from their current path and precede the motivations that then (B2) pull women into computing. (C) Once women have the desire to enter computing, they must also have the resources and means to attend a coding bootcamp, so that $(\mathrm{C} 1)$ they can code, and subsequently obtain a job in the workforce, so that (C2) they do code. 


\section{Transition A: (1) I can't code to (2) I may code}

While most people who choose to attend coding bootcamps do not have college degrees in computing, some do-which indicates they already know that they may code. They may be coming straight out of college and are struggling to find a job, or perhaps they have been out of computing for some time and want to hone their skills. In fact, one woman I interviewed, Amanda, did study computer engineering in college, but she did so in Europe many years ago (in a class that was $50 \%$ women) and felt she needed to improve her skills to move beyond a role in computer testing. One genderqueer individual, Taylor, did not have a college degree (or a high school degree), so they never had the opportunity to choose a major like the other women didinstead, they chose to work in hospitality for several years. For the most part, however, these women did not consider computing in college - though one purposefully left her CS major. Some had bad educational experiences in CS (bad teachers or classroom experiences, including harassment), and others were focused on another path. But over $40 \%$ had specific narratives that said computing was not for them. So far, these findings are consistent with the literature, which predicts that women would not enter computing due to issues of "supply" and the leaky pipeline model (Alper 1993; Berryman 1983; Camp 1997).

\section{$\underline{\text { A1. I can't code }}$}

\section{Bad educational experiences}

Several women recalled having bad educational experiences with computers or in CS specifically, just as the research would predict (Ecklund et al. 2012; Margolis and Fisher 2003). Heather, for example, grew up in the 1980s in the rural midwest, and she always wanted to play on the computer in grade school. But as a young girl, she remembers being told by her teacher, 
“The computers aren't for you; they're for Greg" (Heather, 40, woman). Two others had traumatizing experiences while in CS classes in college. For instance, Michelle was brand new to the subject (and university, after transferring from community college) and found herself completely overwhelmed:

"The first week of class, I think I must have legitimately spent 20 or 30 hours on homework, and I remember like sobbing and thinking this is my first quarter at University and I'm going to fail out and let down my entire family. And it was really clear that everyone else there had previous experience in CS, even though this is the introductory class. I lasted like six weeks into the quarter and then I dropped at the last minute because I was like this is going to ruin my GPA, what am I going to do?” (Michelle, 30, woman)

Nicole, on the other hand, had been passionate about coding for years, but she was harassed in the CS major, as one of a small handful of women:

"So I walked in on a professor watching porn, that was one thing. Regularly, I would just be walking to class and there would be frats all around. I'd get things thrown at my butt on a regular basis, when I was going to class or just sitting in lecture, people just threw things at me. Or heading from class to the dorms back home, there would be groups of guys holding signs with numbers ranking the women from 1 to 10 as we passed by." (Nicole, 30, woman)

These quotes demonstrate just how "chilly" the climate can be for women in CS and what causes them to leave Crawford and MacLeod 1990; Hughes et al. 2017; Seymour and Hewitt 1997; Xie and Shauman 2003.

\section{Limiting beliefs}

As previous research has shown, children are often socialized to conform to their respective gender roles (Eccles 1987; Jacobs 1989; Marini and Brinton 1984; Parsons and Bales 1955). Since computers and technology are seen as masculine domains (Faulkner 2000; Hacker 1989; Mcllwee and Robinson 1992), girls may avoid S/E or computing or simply not consider them as options to pursue (Matyas 1985; Tai et al. 2006). As the literature would predict, many 
of the women I interviewed never considered computing as a college major, and seven of 16 mentioned specific reasons they believed computing was not meant for them. Sarah pictured a computer scientist as "somebody sitting in a basement in a dark room eating Cheetos and looking at ones and zeros on a screen" (Sarah, 35, woman), and Courtney thought computer science was "for nerdy guys who wanted to create video games" (Courtney, 40, woman). Several others believed they were not smart enough or good enough at math to study computing; they bought into the "brilliance narrative" and "geek" mythologies (Margolis and Fisher 2003; Meyer et al. 2015), as illustrated in the following quotes:

"I wasn't really into math and science, but I was really into theater and traditionally dorky things I guess. I told myself a narrative that maybe hindered me in college that I wasn't a science-y person... I didn't really like math, I wasn't that good at it, so I'm like I'm really into singing and having good oral communication skills, and in a way, I think I clung to that narrative for so long that I didn't even consider doing computer science earlier or engineering earlier." (Ashley, 30, woman)

"I honestly thought it was kind of unattainable, or I feel like sometimes the way we talk about software developers and software engineers is like rocket science. I think it's put on this pedestal, and it's really anyone who has the patience... Like it is mentally challenging, but it doesn't mean that it's for the top percentage of people with the highest IQ in the world or whatever, and that's how I thought about it before was that I wouldn't be smart enough to do that." (Sarah, 25, woman)

"I feel like I sort of fell into that mythology that if you're going to be a developer, if you're going to write code, you are building computers in your garage when you were five and you've been hacking the NSA since 11. Like I just assumed even at 24 that I'm way too old to learn this stuff, and I learned that was not true at all." (Elizabeth, 30, woman)

Throughout my interviews, I noticed that many women - even those who did not seem to have prohibitive narratives in their youth - made sure to mention that they were not coding in their spare time and that one did not have to be brilliant to code, indicating their current awareness of and disapproval of these stereotypes.

\section{A2. I May Code}


In order for these women to see computing as a viable career option, they had to overcome their bad experiences with CS and dispel and overcome the limiting narratives they told themselves. In order for this to occur, all respondents indicated that one or more of the following made a difference to them: exposure to coding through their work, people who made them believe they could code, and coding bootcamps catered specifically to women and to those for whom identifying as female has been important in their lives, including transgender, genderqueer, or non-binary individuals ${ }^{3}$. This is the first crack in the leaky pipeline model, suggesting a superior life course model.

\section{Exposure through work}

About half of the respondents gained exposure to coding through work. Though by job description they were in non-technical roles, these women found themselves taking on technical projects, such as creating business intelligence reports or maintaining the company website. Over time, they came to realize that they really enjoyed what they were doing and wanted to pursue it in greater depth, as exemplified in the following quote:

"I didn't really know about any resources and wasn't thinking about it as a career; I just really fell into it. And then the more SQL I learned, I became very good at SQL, and I started expanding and thinking about other languages. My company started to not officially but unofficially move me into business intelligence, data analyst role, but I was like I'm not getting paid for this... SQL is just this one thing that I've learned as like a byproduct of this job, but I actually am really interested in software engineering as a whole." (Kimberly, 30, woman)

In addition, one woman gained initial exposure through a college extension class (for work), and several others solidified their decision to make a career change and attend a coding bootcamp by taking courses online or through a community college.

\footnotetext{
${ }^{3}$ This language is adapted from the all-women coding bootcamps' websites, which define "women" in a similarly inclusive manner.
} 


\section{Influential people}

Almost half of respondents were influenced by people around them, including partners, friends, and mentors. With the exception of one, who had a mentor specifically advise her to attend a coding bootcamp, these networks did not seem to push or pull these women into computing as much as they served to demonstrate by example that it was possible. Several had close friend groups living in Silicon Valley who enjoyed working in tech, and five women had (male) partners who were software developers. Surprisingly, these respondents did not consider their partners to be major motivators to attend a coding bootcamp, though their presence is unmistakable. Instead, respondents highlighted the importance of their partners' supportimplying an underlying (and perhaps more credible) belief in these women's intelligence and ability to code. Ashley's husband even helped her reverse the narrative that she was not good at math:

"I try to be really cautious now of how I talk about my relationship with math. Because my mom was like I just don't like math, I'm not very good at it. And I was like, okay, I'm also not that good at it. And then my husband feels very strongly that we shouldn't talk about math that way. So I'm like, I'm just human at math. That's fine." (Ashley, 30, woman)

Several others living in the Bay Area also stated the importance of meeting people, significantly women, who had attended a coding bootcamp, secured a high-paying job after, and were successfully working in tech. For instance, this is what Amber said of the impact of meeting women who had gone through a coding bootcamp:

"I had met her, I had met this person, like this person was real and she quit [her previous job], went to [a coding bootcamp], and was one of the first people to get a job outside, like before she even finished the course. She told me her first job offer was over $\$ 100,000$ for the year. I was like she must be doing something special... she must be ridiculously smart and I am not... Then my family friend's daughter who's in her midtwenties... went to [a coding bootcamp] as well, graduated, got denied from [a tech company], went back to [the same tech company] and said give me one day...and you're 
going to hire me. She did that, and she still works for them. I was like this is insane, people are actually getting jobs, so I can do it? So I did." (Amber, 35, woman)

\section{Coding bootcamps for women}

As mentioned previously, fourteen of the sixteen respondents in this study attended coding bootcamps which have stated missions to improve gender diversity in tech and only admit individuals who identify as women, including transgender, genderqueer, or gender non-binary persons. Almost all of these respondents said that an all-women's space was very important in their decision to attend a coding bootcamp, and especially for Nicole who experienced harassment in CS while in college. These programs were also known for having a better worklife balance (fewer expected working hours per week on average), being more selective, having good outcomes, and fostering a strong community (which is likely why I gained so many respondents from their active alumni online community) — and the benefits of a good work-life balance and strong community were brought up most frequently in interviews. Many women, including one who was queer and one who was pregnant, mentioned how important it was for them to be in a safe and accepting space-which they assumed they would get in an all-women's program — when going through the stress of learning and switching careers. Additionally, all of the respondents were aware of and truly believed in the missions of these coding bootcamps to empower more women in tech; they knew these programs were for people like them. Although a few worried that they were being oversold on this message and over-promised that they would be more successful on the market due to their gender, they still wanted to be women in tech and part of changing and improving the gender ratio there. As Ashley stated best:

"I think on the first day, one of our instructors, she welcomed us, and then she was like, 'Welcome to the revolution,' and I was like, yeah, this is so amazing! I'm going to be so interesting when I'm 80 years old. People are going to be like, 'Wow, you were in 
engineering when there weren't that many women,' and I'll be like, yes, I was so revolutionary." (Ashley, 30, woman)

Through the impact of exposure at work, influential people, and coding bootcamps for women, these respondents were able to overcome the bad educational experiences and limiting beliefs that told them they could not code. In other words, those things that pushed them out of the "pipeline" did not have to keep them out of computing any longer. The realization may have come late, but they realized it was possible for them to code.

\section{Transition B: (1) I'm on another path to (2) I want to code (pushes and pulls)}

Existing research that considers multiple paths to computing focuses on motivations that pull people into computing (von Hellens et al. 2000; Leventman 2007; Turner, Bernt, and Pecora 2002), but none have seriously acknowledged the importance of context or the particular situations that arise in one's life course that cause a person to look up from their current path and allow themselves to be pulled into computing in the first place. Indeed, before they considered going to a coding bootcamp, half of these women found themselves with monetary and/or employment needs, while the other half were dissatisfied in their previous jobs and looking for a change. In addition to these situational "pushes" off of their previous paths, all of the women also spoke of motivations that pulled them to computing - whether due to their interest in coding, wanting a better lifestyle through tech, or desiring a new, exciting career in computing. Although I have chosen to emphasize the distinction between these pushes and pulls, respondents frequently spoke of the two together as they compared and contrasted their previous careers with their current ones. These comparisons are critical because they function to influence the way in which these women think and feel about computing and their new careers as software developers in tech. 


\section{B1. I'm on another path (situational "pushes")}

\section{Monetary or employment needs}

Exactly half of the respondents found themselves in need of employment and/or more money, often due to extenuating circumstances that were out of their control (and sometimes more than one at once). For instance, two women had family members who suddenly passed away or became very ill. Although they had planned for careers in other fields, they pivoted to pursue a high paying career in tech to help provide support for their families. A few women unexpectedly found themselves unemployed and saw a job in tech as a good alternative career. Four other women found themselves underemployed and searching for a better career path. Of these, two chose computing primarily because it was their desired field of interest, while the other two chose it primarily to meet their monetary goals.

\section{Career dissatisfaction}

The other half of respondents did not have the same monetary or employment needs but instead desired a career change, due to dissatisfaction in their previous careers. Interestingly, while research has shown that women leave computing due to extreme work pressures, long hours, difficulties balancing work and family, a "chilly climate," changes in professional interests, and dissatisfaction with pay and promotion (Ceci and Williams 2011; Frehill 2012; Hewlett et al. 2008; Hunt 2016; Stephan and Levin 2005), data from several respondents indicate that they left their previous jobs and entered computing due to the same or similar reasons. For instance, several were bored in their previous work and wanted more of a challenge. As Melissa stated,

"I was working in the nonprofit sector for eight years, and I really loved, it but I sort of reached a point in my career where I didn't feel like I was learning and growing the way I 
wanted to be. I had kind of plateaued in a way, so I was considering...going to grad school for nonprofit administration, but then I thought I might end up in the same career that I am today and be paid maybe a little bit more but still be doing the same thing and still not really learning and growing but kind of stagnating" (Melissa, 30, woman)

Another three were burned out from their previous careers, including two former teachers and a nurse. As one of the former teachers Amber said, “I was working 12 to 14 hour days, I didn't have any money to do anything or go anywhere, I missed so many weddings and bachelorette parties with friends and birthdays and stuff because I was so broke" (Amber, 35, woman). Another left her company of over twenty years due to its toxic culture. Of course, this is not to say that these women cannot or will not eventually leave computing for similar reasons, but so far, those who now have jobs in tech have seen an improvement.

\section{B2. I want to code (motivational "pulls")}

From this data, I identified three internal motivations or drivers these women had for entering computing. Every single woman thought that computing was interesting, challenging, and enjoyable. A few even saw it as their passion, which previously lay dormant - either because of negative educational experiences or because they were unaware of their interest. For some, coding was the next, new exciting career to pursue after the conclusion of their first. But for many, coding was equally if not more enticing due to having a good career with a great salary and lifestyle.

\section{Interest and enjoyment}

Again, while all of the women liked and enjoyed computing, some loved it more than others. In particular, Nicole always knew she was passionate about computers and coding; even at a young age, she was building computers at home and started a robotics teams at school. She entered college as a CS major but dropped out due to harassment and switched to another 
technical major. When her first career suddenly ended due to health issues she developed in the workplace, she stumbled upon coding bootcamps as a "great second chance for folks who want to give it another shot" (Nicole, 30, woman)—but this time, in an all-women's space. A couple other women never really knew what they wanted to study in college but "just floated from thing to thing just trying things out" (Tiffany, 30, woman) and eventually settled on a major.

Eventually however, they found computing and quickly knew they loved it and wanted to pursue it as a career. Five other women very much enjoyed their first careers but were looking forward to an exciting new career in computing. As Jen summed up best, “ I really did enjoy my first career, and I still enjoy it, and I think at that time where I was at it was the perfect fit... But there's something about the newness and the excitement of [coding] and learning something new that I really enjoy" (Jen, 35, woman).

Significantly, several women also stated how much they like computing and are interested in it by comparing it to what they have done in the past:

"I don't know how to explain it, but I think one of the things that made me feel like this was a good direction for me to be going in was the fact that I could just lose myself in it for really long stretches of time and not even notice, whereas a lot of the other time when I was doing the social media work, like oh my God, it just made me miserable. I felt like I was watching the clock, and I just don't usually feel that way with [coding]." (Elizabeth, 30, woman)

"It's very interesting. Every day it's a new task; you learn a lot. Like at previous jobs, it would slow down, basically you would go through the same routine over and over, and here it's like technology is evolving so fast it's hard to keep up sometimes, but because you're given at every point of time only one task, you can achieve something." (Amanda, 35, woman)

Finally, several women were quick to say that while they really like computing, they do not love it so much that they would do it on the weekends or in their spare time-specifically in contrast to the "geek" stereotype, which many were familiar with (though they did not refer to it in specific terms). As Michelle said best, 
"I couldn't do [computing] if I didn't like it, but by the same token, I think the kind of industry ideas that I love coding at the exclusion of all other loves, I would go home and spend all my time...no. Like no. I'm not going to write a Wiki on how to take care of my cat, I'm not going to program some Arduino tool to like control my thermostat because the built-in controls are not good enough, and both of those things are actual things that coders I asked actually did, and I was like, okay, but the sun is out. Go and have a life. So yes, I like it a lot, not to the exclusion of other things, and I think in this industry that's kind of unusual." (Michelle, 30, woman)

\section{Lifestyle benefits}

Almost all of the women, including those passionate about computing, highlighted the incredible benefits that accompany a career as a software developer in tech. Money was mentioned most often. For Elizabeth, it let her "live in a nice place, go on a nice vacation, and still set money aside in savings. The salary alone changed things" (Elizabeth, 30, woman). Indeed, with the exception of one, all expected and saw an increase in their salary after attending a coding bootcamp — sometimes multiplied by a factor of two or more. However, as big of a difference as money made, it was just one of many benefits, as indicated by the following quote:

"I like how you can build a lifestyle around a software engineering job. So I work remotely. It means I have a lot more flexibility, so I live with my two dogs; they're usually at my feet when I'm typing. My boss doesn't care when I get my work done, as long as I do get my work done, so if I want to leave early to go hiking and then do more work, it's just much more flexible. I love working from home, it means I can travel if I need to, it means I can have friends over, it means I can co-work with people. In the winter, it means I don't get sick as often because I'm not around co-workers." (Nicole, 30, woman)

Indeed, most women hoped for and received benefits that were far better than before. In other words, yet again, many of these women discussed the advantages of their current work over previous jobs and careers, as illustrated in the following:

"I [used] to work 10 to 12 hour days, [and] I was always really stressed and really tired, and it was just hard and frustrating often. And now I'm working really hard but on things that are really interesting and with realistic deadlines and a really supportive team and manager, and I feel like that weight has lifted, and now I can think about what are the 
activities and things that I want to do for myself, and I do have the time and energy to participate in them. So that's been hugely transformational." (Melissa, 30, woman)

"I mean, there's definitely stressful days and stressful moments, but I work 40 hours a week. I was working 45 to 50 for 25 grand less before. So now it's like I have a great work-life balance, I'm interested in the work that I'm doing, I'm super challenged, and landed on a team that's really supportive, learning so so much, and being in a space where that's a comfortable thing to do." (Jen, 35, woman)

Respondents said the benefits of working in tech as software developers helped provide "independence" and "freedom," and one said that being able to spend money on things they cared about was "liberating." These overwhelmingly positive statements from women about their improved lifestyles are quite surprising, given the ways in which women are said to be pushed out of technical work. Still, just because so many women were glowing about the benefits does not mean that they did not also expect to and have negative experiences working as programmers in tech, as popular discourse would predict.

\section{Downsides of tech culture}

While all of these women chose to go into computing and had positive things to say about the work, many also had negative experiences since being software developers in tech—which all expected to have and were not particularly surprised about (they were rather grateful when they did not have any bad experiences). Every women stated that she was aware of the popular discourse of toxic masculinity in tech culture, and all felt there was much room for improvement. However, their knowledge of an abrasive tech culture was surprisingly downplayed and clearly did not hold them back from seeking a career in tech. Indeed, several of these women stated that they faced similar or worse work cultures in their previous careers. Stephanie, who previously consulted in a variety of different industries, said,

"I would say that that culture still exists no matter where you go. I worked in financial services - boys' club. I worked in energy_-boy's club. It exists everywhere. It's just 
certain industries have had their pressure for so long that they can hide it better." (Stephanie, 40, woman)

Heather, who used to work in nursing said,

"[If] the physician doesn't like you, [they] will withhold pain meds from your patient. Because they thought you were uppity. Or they're just in a bad mood. Everyone's going to suffer. So I didn't think it was possible for the tech bros to have that kind of power, and they don't." (Heather, 40, woman)

Coming from the legal sector, Jen said, "there's a lot of toxic masculinity there too, like abrasive lead attorneys who breathe at you weird and stand behind you and try to intimidate you. I had already dealt with all of that already, and I don't intimidate easy either' (Jen, 35, woman). As such, while no one minimized or downplayed the reality that tech has a bad culture and has much room for improvement, many women with previous careers indicated that a similarly poor culture existed elsewhere, too. Tech culture was not about to keep them from entering computing.

\section{Transition C: (C1) I can code to (C2) I do code}

Even if one knows that she may code and that she wants to code, she still must have the ability to make that transition happen - in this case, by way of a coding bootcamp education and then to a career in tech as a software developer. About half of the respondents attended a fulltime coding bootcamp that cost over $\$ 15,000$ for 12 weeks. The other half of respondents attended a full-time coding bootcamp that was free for six months, but they had to pay for their own living expenses during that time. And still, upon completion of a coding bootcamp, graduates must be prepared to be unemployed and looking for jobs for multiple months or more. All of the respondents had the goal of working as software developers in tech after graduation, and for the 12 respondents who had actively sought a job (by the time I spoke to them), they were all able to secure one in six months - meaning they do code. In fact, none described a real 
struggle, which is quite surprising (and might also be due to self-selection into being interviewed). For the four who do not yet have jobs, they purposely delayed their search due to health issues, having a baby, or being in the process of moving.

\section{$\underline{\text { C1. I can code }}$}

While the ability to afford a coding bootcamp education is in no way a trivial matter, it is still a fraction of the time and cost of a bachelor's degree or a master's degree (if one could even get into a master's program in computing from a non-technical background). The average cost and time of a coding bootcamp in 2018 was $\$ 11,900$ for 14.3 weeks (Eggleston 2018b), compared to 2 or more years at an average cost of $\$ 8,000$ per year for (in-state) tuition and fees for a traditional bachelor's or master's degree (Ma et al. 2018). Some coding bootcamps help with special loan plans or scholarships, often for women and underrepresented minorities in tech. But more uniquely, a few coding bootcamps are either free or have delayed payment plans, which take a percentage of a graduate's first year salary once they get a job (though only one respondent from this sample had and chose that option). For some, this actually makes it possible to attend a coding bootcamp, where it was not possible before. In fact, several women said they were considering going back to college for a more traditional computing education but felt that the time and money were too great. Therefore, while a coding bootcamp still requires a fair amount of resources to attend, the time and money is considerably less than other options.

\section{Financial supports}

Six of the 16 respondents were married at the time that they attended a coding bootcamp, and four were married to software engineers working in tech. They all received financial support from their spouses, minimally to cover living expenses, and several mentioned receiving critical 
emotional support from their husbands, as well. When speaking of her spouse, Melissa said, "I think everyone should have a person in their life who tells them that everything is going to be okay and you're not dumb no matter how much you think you are. I think that was such a key factor in me being successful" (Melissa, 30, woman). No one mentioned seeking tutelage from their spouse (in fact, a few actively avoided it), but some accepted it when needed. A few women said they had committed partners at the time they attended a coding bootcamp, with whom they shared living expenses. And several other women received financial support from their parents or received help from their friends with living expenses. Only one woman mentioned taking out a loan (another received a loan from her family), and many women also drew from their personal savings from work.

Of the five women who grew up in lower class backgrounds, two were unmarried and without clear financial stability at the time of attending a coding bootcamp - and only one, Christina, said she was truly scared about the risk she was taking. This implies that while it is not common to attend a coding bootcamp while in a precarious financial situation, it is possible though likely much, much harder. As Michelle, who came from a middle-class background, made sure to note,

"I think the people who did best at [the coding bootcamp], frankly you have to be middleincome, you have to have the social safety net, like you have to have some support whether it's a spouse, partner, your parents, something, and I hate to say that. I don't want that to be the case, but the program is too intense to succeed I think if you have to be focusing on other stuff." (Michelle, 30, woman)

Michelle also indicated that several women dropped out of the coding bootcamp because their loans did not cover the cost of living and that one even became homeless.

\section{C2. I do code}


As mentioned previously, these women had relatively little difficulty getting a jobs in tech after graduation from a coding bootcamp. They all secured a job as a programmer in a six months or less, which seemed to meet their expectations going into the coding bootcamps, and all said they worked very hard in the program because they wanted a job after. Their average starting salary was $\$ 90,000$. Of course, several of them also chose their coding bootcamp in part because it guaranteed an internship with a company as part of its formal program — and several women were able to turn that into a full-time job. A few others used connections they made at their coding bootcamp to get their first job, which further demonstrates the importance of these strong communities. Still, a few mentioned how much they had to hustle on their own, outside of the coding bootcamp, to get a job. The following quote is from Christina, who was also the least financially secure when attending a coding bootcamp:

"It wasn't from [the coding bootcamp] that I felt like I got a job. Like I did a bunch of other things on my own, like I went to a bunch of hackathons, and that's how I got a bunch of interviews. It's a really cool community there. I went to a bunch of education hackathons and travel hackathons and things like that. So you had to do extra stuff." (Christina, 25, woman)

It may be that Christina perceived these additional activities as harder to do or felt extra pressure to do them due to her financial situation. Again, it is likely this sample is unique in their relative ease to secure a job after graduation (due to self-selection); however, these were some of the ways in which these women were able to turn I can code into I do code - the final part of the process to enter computing.

\section{Conclusion}

The leaky pipeline model argues that there is a tight link between one's high school and college education and subsequent work in $\mathrm{S} / \mathrm{E}$, and that attrition occurs for women all along the way. However, this model leaves no room for women to enter S/E or computing later in life- 
such that the women who transition into computing through coding bootcamps cannot be explained. In contrast, the life course model acknowledges the non-linear paths of many people's lives and can account for these women who change direction and enter computing, even after first selecting a non-technical major or career. Unfortunately, the majority of research that supports this model lacks empirical evidence demonstrating that women in fact do enter computing post-college and, crucially, the processes they go through to actually make the change.

To address this theoretical gap, I leveraged the strategic site of coding bootcamps to better understand how and why women enter computing later in life-despite them not choosing computing before and the declining rates of women in computing. Significantly, I have identified three major transitions that women must go through. First, they must overcome limiting myths and narratives to see coding as a viable option available to them. Second, they must be in a situation that causes them to step off their current path and be motivated to pursue computing. Third, they must have the means like time and money to attend a coding bootcamp and finally secure a job in tech as a programmer. As such, this research rejects the leaky pipeline model due to its limitations and extends the life course model to include the processes by which women enter computing later in life.

Although these women were aware of the negative discourse surrounding tech culture, they still chose to enter computing. They had no doubt that tech culture treated women poorly, but several (correctly) imagined that it could not be worse than their previous work cultures. Impressively, even those who had experienced a "chilly" climate in education were able to overcome previous and (imagined) future bad experiences doing technical work, largely because they enjoyed the work and had comparatively better benefits. Many of the women highlighted 
the ways in which a higher salary, fewer hours, and a better work-life balance improve their lives. These data seem to be in opposition to findings that women leave computing due to extreme work pressure or challenges balancing work and family and (Ceci and Williams 2011; Hewlett et al. 2008; Stephan and Levin 2005), and in part, due to disappointment with pay and promotion - though it does not rule out that they may later leave due to facing discrimination in the workplace or having a lack of mentorship and networks (Hunt 2016). Still, these women's statements lie in stark contrast to many popular implications that tech is uniformly terrible to women.

One limitation of this study was that women were selected based on their attending a coding bootcamp to enter computing. So while three end states (often via three transitions) were identified as being in common to all attendees, this research cannot speak to reasons that women might choose not to attend a coding bootcamp. For instance, it may be that negative stereotypes or bad educational experiences in youth actually deter many women from considering computing or a coding bootcamp. And in this sense, the pipeline model would be correct—supply-side factors do dissuade women from entering computing in the first place. Or, perhaps many women consider computing but are turned off by narratives of the toxic tech culture; from the data, it is hard to say. Another limitation of this study was that all of these women attended one of four coding bootcamps, with the vast majority having attended one of two, both of which limited their programs to women. These same two coding bootcamps are also known for being particularly selective, which means the women they admit may very well be exceptional in certain ways-for instance, they may be predisposed to being a good fit for the program, succeeding in it, and getting a job in tech after. Indeed, I did not speak to any women who were not successful in completing a coding bootcamp, and everyone who had actively looked had secured a job. Future 
research should consider those women who have made transitions $\mathrm{A}$ and $\mathrm{B}$, for instance, but are stuck at $\mathrm{C}$ - whether due to financial or other barriers or the inability to get hired by a tech company.

This research could also be improved by increasing the demographic diversity of the respondents. Ages in the sample ranged from the mid-20s to mid-40s, with an average age of 33 - meaning that most of these women had at least two more decades of expected work left. For the two women who were over 40, both were doing well financially and were not in need of work immediately post-graduation (neither were actively looking for work when I interviewed them, due to other circumstances). In terms of race, two identified as mixed race, while the rest were either White or Asian. These statistics are not entirely surprising, given that coding bootcamps are also overwhelmingly White and Asian (66\% and 16\% respectively) (Eggleston 2018a), but it is quite difficult for me to contribute to the research as to how and why Black and Latinx women attend coding bootcamps, for instance. Indeed, more research should be conducted on how intersectional qualities such as age and race affect those women who go to coding bootcamps and enter tech as programmers in efforts to improve diversity in more meaningful and impactful ways.

With regards to gender, this study was motivated by previous literature that focuses on the dearth of women in tech and computing. However, my sample only included one person who identified as genderqueer, so it is difficult to say how identifying as transgender or gender nonbinary, for instance, might affect one's interest and ability to attend a coding bootcamp. In addition, future research could benefit from gaining a deeper understanding of why men attend coding bootcamps. Based on my interviews with five men, transitions B and C are both relevant and applicable to them as well. However, none suggested that they had to go through transition 
A — which puts them in a very different situation and at a huge advantage. That being said, men might face different challenges altogether that were not uncovered in the interviews I conducted.

Again, this study rejects the pipeline model for its limitations and extends the life course model by providing empirical evidence on how and why women enter computing later in life. Specifically, women must successfully achieve three end states, often by completing three transitions that move all the way from "I can't code" to "I do code" — and these transitions depend not just on motivational factors but context as well. Furthermore, women choose to enter computing because they enjoy it and receive far greater benefits. While they acknowledge a poor tech culture, it does not deter them - and speaking from previous experience, several note that the industry is no worse than others. Tech may not be so uniquely and uniformly terrible to women, as the media might have us think. I argue that, currently, the existing literature on the pipeline and life course model, as well as negative tech culture discourse, underestimate the resilience of women in computing. Continuing to focus solely on why women are pushed out and leave computing might serve to exacerbate the problem. This research highlights how and why women come back and enter computing, despite the odds.

Finally, this study shows that if we desire to reduce the gender gap in computing and tech, there is an opportunity to recruit women who are in the later stages of their (non-technical) educational and occupational careers. And possibly, having a greater diversity of previous experiences might come with advantages. In particular, these women may appreciate their careers as programmers in tech more, due to their ability to compare their new careers with what they had in the past - in many cases, they seem to find that they make more money and receive better benefits in tech; plus, they enjoy a new challenge. Time will tell, but it is possible that 
these factors stand to actually improve women's retention in computing and tech. The more women who join the revolution now, the easier it may be for generations to come. 


\section{References}

Alper, Joe. 1993. "The Pipeline Is Leaking Women All the Way Along." Science 260(5106):409-11.

Bailyn, Lotte. 2003. “Academic Careers and Gender Equity: Lessons Learned from MIT.” Gender, Work \& Organization 10(2):137-53.

Becker, Gary. 1957. The Economics of Discrimination. Chicago: University of Chicago Press.

Becker, Gary S. 1985. "Human Capital, Effort, and the Sexual Division of Labor.” Journal of Labor Economics 3(1):33-58.

Becker, Joanne Rossi. 1981. "Differential Treatment of Females and Males in Mathematics Classes." Journal for Research in Mathematics Education 12(1):40-53.

Beckhusen, Julia. 2016. Occupations in Information Technology. American Community Survey Reports. ACS-35. Washington, DC: U.S. Census Bureau.

Benner, Katie. 2017. "Women in Tech Speak Frankly on Culture of Harassment." The New York Times, December 22.

Berryman, Sue E. 1983. Who Will Do Science? Trends, and Their Causes in Minority and Female Representation among Holders of Advanced Degrees in Science and Mathematics. A Special Report. New York, NY: Rockefeller Foundation.

Bottia, Martha Cecilia, Elizabeth Stearns, Roslyn Arlin Mickelson, Stephanie Moller, and Lauren Valentino. 2015. "Growing the Roots of STEM Majors: Female Math and Science High School Faculty and the Participation of Students in STEM.” Economics of Education Review 45:14-27.

Camp, Tracy. 1997. "The Incredible Shrinking Pipeline." Communications of the ACM, October, $103-10$. 
Ceci, Stephen J. and Wendy M. Williams. 2011. “Understanding Current Causes of Women's Underrepresentation in Science." Proceedings of the National Academy of Sciences 108(8):3157-62.

Ceci, Stephen J., Wendy M. Williams, and Susan M. Barnett. 2009. “Women’s Underrepresentation in Science: Sociocultural and Biological Considerations." Psychological Bulletin 135(2):218-61.

Committee on Maximizing the Potential of Women in Academic Science and Engineering and Committee on Science, Engineering, and Public Policy. 2007. Beyond Bias and Barriers: Fulfilling the Potential of Women in Academic Science and Engineering. Washington, D.C.: The National Academies Press.

Cooper, Marianne. 2000. "Being the 'Go-To Guy': Fatherhood, Masculinity, and the Organization of Work in Silicon Valley.” Qualitative Sociology 23(4):379-405.

Crawford, Mary and Margo MacLeod. 1990. "Gender in the College Classroom: An Assessment of the 'Chilly Climate' for Women.” Sex Roles 23(3):101-22.

Eccles, Jacquelynne S. 1987. “Gender Roles and Women's Achievement-Related Decisions.” Psychology of Women Quarterly 11(2):135-72.

Ecklund, Elaine Howard, Anne E. Lincoln, and Cassandra Tansey. 2012. "Gender Segregation in Elite Academic Science.” Gender \& Society 26(5):693-717.

Eggleston, Liz. 2018a. "2018 Coding Bootcamp Alumni Outcomes \& Demographics Report.” Retrieved April 15, 2019 (https://www.coursereport.com/reports/coding-bootcamp-jobplacement-2018).

Eggleston, Liz. 2018b. "2018 Coding Bootcamp Market Size Study.” Retrieved October 23, 2018 (https://www.coursereport.com/reports/2018-coding-bootcamp-market-size- 
research).

Farmer, Helen S., James L. Wardrop, and Susanne C. Rotella. 1999. “Antecedent Factors Differentiating Women and Men in Science/Nonscience Careers.” Psychology of Women Quarterly 23(4):763-80.

Faulkner, Wendy. 2000. “Dualisms, Hierarchies and Gender in Engineering.” Social Studies of Science 30(5):759-92.

Frehill, Lisa M. 2012. “Gender and Career Outcomes of U.S. Engineers.” International Journal of Gender, Science and Technology 4(2):148-66.

Glass, Jennifer L., Sharon Sassler, Yael Levitte, and Katherine M. Michelmore. 2013. 'What's So Special about STEM? A Comparison of Women's Retention in STEM and Professional Occupations." Social Forces 92(2):723-56.

Hacker, Sally. 1989. Pleasure, Power, and Technology: Some Tales of Gender, Engineering, and the Cooperative Workplace. Boston: Unwin Hyman.

Heilman, Madeline E. 2001. "Description and Prescription: How Gender Stereotypes Prevent Women's Ascent Up the Organizational Ladder." Journal of Social Issues 57(4):657-74. von Hellens, L. A., R. Pringle, S. H. Nielsen, and A. Greenhill. 2000. "People, Business and IT Skills: The Perspective of Women in the IT Industry." Pp. 152-157 in Proceedings of the 2000 ACM SIGCPR Conference on Computer Personnel Research, SIGCPR '00. New York, NY, USA: ACM.

Hewlett, Sylvia Ann, Carolyn Buck Luce, Lisa J. Servon, and Laura Sherbin. 2008. The Athena Factor: Reversing the Brain Drain in Science, Engineering, and Technology. 10094. Harvard Business Review Research Report.

Hughes, Cayce C., Kristen Schilt, Bridget K. Gorman, and Jenifer L. Bratter. 2017. "Framing the 
Faculty Gender Gap: A View from STEM Doctoral Students.” Gender, Work \& Organization 24(4):398-416.

Hunt, Jennifer. 2016. “Why Do Women Leave Science and Engineering?” ILR Review 69(1):199-226.

Hunt, Jennifer, Jean-Philippe Garant, Hannah Herman, and David J. Munroe. 2013. "Why Are Women Underrepresented amongst Patentees?” Research Policy 42(4):831-43.

Jacobs, Jerry A. 1989. Revolving Doors: Sex Segregation and Women's Careers. Stanford, CA: Stanford University Press.

Kanter, Rosabeth Moss. 1977. Work and Family in the United States: A Critical Review and Agenda for Research and Policy. Russell Sage Foundation.

Kelly, Alison. 1985. "The Construction of Masculine Science.” British Journal of Sociology of Education 6(2):133-54.

Lehman, Kathleen J., Linda J. Sax, and Hilary B. Zimmerman. 2016. "Women Planning to Major in Computer Science: Who Are They and What Makes Them Unique?" Computer Science Education 26(4):277-98.

Leventman, Paula G. 2007. "Multiple Pathways toward Gender Equity in the United States Information Technology Workforce.” Pp. 211-38 in Reconfiguring the Firewall: Recruiting Women to Information Technology across Culture and Continents, edited by C. J. Burger, E. G. Creamer, and P. S. Meszaros. Wellesley, MA: A K Peters, Ltd. Lim, Kyung Min. 2016. "Major Matters: Exploration of the Gender Wage Gap among STEM Graduates." UCLA.

Ma, Jennifer, Sandy Baum, Matea Pender, and CJ Libassi. 2018. Trends in College Pricing 2018. New York: The College Board. 
Margolis, Jane and Allan Fisher. 2003. Unlocking the Clubhouse: Women in Computing. MIT Press.

Marini, Margaret Mooney and Mary C. Brinton. 1984. "Sex-Typing in Occupational Socialization.” Pp. 192-232 in Sex segregation in the workplace, edited by B. F. Reskin. Washington, D.C: National Academy Press.

Marx, David M. and Jasmin S. Roman. 2002. “Female Role Models: Protecting Women’s Math Test Performance.” Personality and Social Psychology Bulletin 28(9):1183-93.

Matyas, M. L. 1985. “Obstacles and Constraints on Women in Science: Preparation and Participation in the Scientific Community." in Women in science: A report from the field, edited by J. B. Khale. London: Falmer Press.

McIlwee, Judith S. and J. Gregg Robinson. 1992. Women in Engineering: Gender, Power, and Workplace Culture. Albany: SUNY Press.

Meyer, Meredith, Andrei Cimpian, and Sarah-Jane Leslie. 2015. "Women Are Underrepresented in Fields Where Success Is Believed to Require Brilliance.” Frontiers in Psychology 6.

Michelmore, Katherine and Sharon Sassler. 2016. "Explaining the Gender Wage Gap in STEM: Does Field Sex Composition Matter?” RSF: The Russell Sage Foundation Journal of the Social Sciences 2(4):194-215.

Mincer, Jacob and Solomon Polachek. 1974. "Family Investments in Human Capital: Earnings of Women.” Journal of Political Economy 82(2, Part 2):S76-108.

Mundy, Liza. 2017. "Why Is Silicon Valley So Awful to Women? - The Atlantic.” Retrieved December 11, 2018 (https://www.theatlantic.com/magazine/archive/2017/04/why-issilicon-valley-so-awful-to-women/517788/).

NCES, IPEDS (National Center for Education Statistics, Integrated Postsecondary Education 
Data System). 2018. Bachelor's degrees conferred to females by postsecondary institutions, by race/ethnicity and field of study: 2015-16 and 2016-17. Retrieved April 16, 2019 (https://nces.ed.gov/programs/digest/d18/tables/dt18_322.50.asp).

NSF (National Science Foundation). 2018. Science and Engineering Indicators 2018. NSB2018-1. Alexandria, VA. Retrieved April 16, 2019 (https://www.nsf.gov/statistics/2018/nsb20181/report).

NSF, NCSES (National Science Foundation, National Center for Science and Engineering Statistics). 2019. Women, Minorities, and Persons with Disabilities in Science and Engineering: 2019. Special Report NSF 19-304. Alexandria, VA. Retrieved April 16, 2019 (https://www.nsf.gov/statistics/wmpd).

Parsons, Talcott and Robert Freed Bales. 1955. Family, Socialization and Interaction Process. Glencoe, Illinois: Free Press.

Preston, Anne E. 1994. "Why Have All the Women Gone? A Study of Exit of Women from the Science and Engineering Professions.” The American Economic Review 84(5):1446-62.

Preston, Anne E. 2004. Leaving Science. 1 edition. New York: Russell Sage Foundation.

Rosenfeld, Rachel A. and Kenneth I. Spenner. 1992. "Occupational Sex Segregation and Women's Early Career Job Shifts.” Work and Occupations 19(4):424-49.

Seymour, Elaine and Nancy Hewitt. 1997. Talking about Leaving: Why Undergraduates Leave the Sciences. Boulder, CO: Westview Press.

Sonnert, Gerhard and Gerald Holton. 1995. Who Succeeds in Science: The Gender Dimension. None edition. New Brunswick, N.J: Rutgers University Press.

St. Rose, Andresse. 2010. "STEM Major Choice and the Gender Pay Gap." On Campus with Women. Retrieved May 17, 2019 
(http://ink.galegroup.com/apps/doc/A238751293/AONE?sid=googlescholar).

Stephan, Paula E. and Sharon G. Levin. 2005. "Leaving Careers in IT: Gender Differences in Retention.” The Journal of Technology Transfer 30(4):383-96.

Tai, Robert H., Philip M. Sadler, and Joel J. Mintzes. 2006. "Factors Influencing College Science Success." Journal of College Science Teaching 36(1):52-56.

Thébaud, Sarah and Maria Charles. 2018. "Segregation, Stereotypes, and STEM.” Social Sciences 7(7):111.

Turner, Sandra V., Phyllis W. Bernt, and Norma Pecora. 2002. "Why Women Choose Information Technology Careers: Educational, Social, and Familial Influences." Paper presented at the Annual Meeting of the American Educational Research Association, New Orleans, LA.

Xie, Yu and Kimberlee A. Shauman. 2003. Women in Science: Career Processes and Outcomes. Cambridge, Mass.: Harvard University Press. 
Table 1: Respondent Profiles

\begin{tabular}{|c|c|c|c|c|c|c|c|c|}
\hline Name & Age & Gender & Race & Childhood SES & $\begin{array}{l}\text { Educational } \\
\text { Background }\end{array}$ & Highest Degree & Previous Work & Interview Date \\
\hline Christina & 25 & Woman & Asian & Lower & Non-technical & Bachelor's & Non-technical & July 2018 \\
\hline Michelle & 30 & Woman & Mixed & Middle & Non-technical & Master's & Technical & August 2018 \\
\hline Nicole & 30 & Woman & White & Middle & Technical & Bachelor's & Technical & August 2018 \\
\hline Elizabeth & 30 & Woman & White & Middle & Non-technical & Master's & Non-technical & August 2018 \\
\hline Tiffany & 30 & Woman & Asian & Upper Middle & Non-technical & Bachelor's & Non-technical & August 2018 \\
\hline Kimberly & 30 & Woman & White & Upper Middle & Non-technical & Bachelor's & Non-technical & August 2018 \\
\hline Melissa & 30 & Woman & White & Middle & Non-technical & Bachelor's & Non-technical & July 2018 \\
\hline Ashley & 30 & Woman & Asian & Middle & Non-technical & Master's & Non-technical & July 2018 \\
\hline Taylor & 30 & Genderqueer & White & Middle & Non-technical & Some high school & Non-technical & August 2018 \\
\hline Amanda & 35 & Woman & White & Lower & Technical & Bachelor's & Technical & August 2018 \\
\hline Sarah & 35 & Woman & White & Middle & Non-technical & Bachelor's & Non-technical & July 2018 \\
\hline Jen & 35 & Woman & White & Upper Middle & Non-technical & Bachelor's & Non-technical & August 2018 \\
\hline Amber & 35 & Woman & Asian & Middle & Non-technical & Bachelor's & Non-technical & August 2018 \\
\hline Courtney & 40 & Woman & Mixed & Lower & Non-technical & Master's & Non-technical & July 2018 \\
\hline Heather & 40 & Woman & White & Lower & Non-technical & Master's & Non-technical & August 2018 \\
\hline Stephanie & 40 & Woman & Asian & Lower & Non-technical & Master's & Non-technical & July 2018 \\
\hline
\end{tabular}

